\title{
Implementación estratégica de atención al usuario durante la pandemia COVID-19 (SARS-CoV-2) CECAMET, 2020- primer trimestre 2021
}

\author{
Strategic implementation of customer service during the pandemic \\ COVID-19 (SARS-CoV-2) CECAMET, 2020- first quarter 2021
}

Manuel Fernández Torrano,* Reina Virginia Del Ángel Leyvał

\section{RESUMEN}

En la Comisión Estatal de Conciliación y Arbitraje Médico de Tabasco (CECAMET), para la atención eficiente al usuario durante la pandemia COVID-19, se ubicó al personal de mayor edad, así como aquellos de movilidades reales, aplicando la opción home office y con el personal de menor edad se implementó una estrategia de guardias en las diversas unidades de atención para cumplir en tiempo y forma todos los asuntos solicitados; de la misma manera se habilitó un buzón de quejas, para atender cualquier asunto que el usuario solicitara en cualquier momento, habilitándose de la misma forma el WhatsApp institucional y módulos itinerantes en nuestras redes sociales, las cuales nos mantuvieron en contacto directo con los usuarios, reportándose 7,300 seguidores y 5,474 beneficiados. Nuestro sistema de capacitación continúa hacia el sector salud y público en general, se reestructura aplicándose la modalidad en línea, beneficiando a un total de 5,139 usuarios.

Palabras clave: Pandemia COVID-19, buzón de quejas, redes sociales, modalidad en línea.

\begin{abstract}
In the State Commission for Conciliation and Medical Arbitration of Tabasco (CECAMET), for the efficient attention to the user during the COVID-19 pandemic, older personnel were located, as well as those with real mobility, applying the home office option and with the Minor staff implemented a strategy of guards in the various care units to comply with all the requested matters in a timely manner; In the same way, a complaints box was set up to attend to any matter that the user requested at any time, enabling the institutional WhatsApp and itinerant modules in our social networks in the same way, which kept us in direct contact with the users by reporting 7,300 followers and 5,474 beneficiaries. Our continuous training system for the health sector and the general public is restructured by applying the online modality, benefiting a total of 5,139 users.
\end{abstract}

Keywords: COVID-19 pandemic, complaints box, social networks, online mode.

\begin{abstract}
* Médico Pediatra. Comisionado Estatal de Comisión Estatal de Conciliación y Arbitraje Médico del Estado de Tabasco. Coordinador General de la Comisión de Bioética del Estado de Tabasco, México.

₹ Maestra en Ciencias de la Educación, Bióloga. Titular de la Unidad de Enseñanza, Investigación y Calidad. Miembro del Comité Estatal Interinstitucional para la Formación de Recursos Humanos e Investigación para la Salud del Estado de Tabasco, México.
\end{abstract}

Correspondencia: MFT, cecamet@tabasco.gob.mx, ueic.cecamett@gmail.com Conflicto de intereses: LOS autores declaran no tener conflicto de intereses. Citar como: Fernández TM, Del Ángel LRV. Implementación estratégica de atención al usuario durante la pandemia COVID-19 (SARS-COV-2) CECAMET, 2020- primer trimestre 2021. Rev CONAMED. 2021; 26(supl. 1): s39-s45. https:// dx.doi.org/10.35366/102580 Financiamiento: No hubo financiamiento.

Recibido: 18/10/2021. Aceptado: 18/10/2021. 


\section{INTRODUCCIÓN}

Es necesario recordar que tuvimos la buena fortuna en México y Tabasco de conocer, aproximadamente tres meses antes, la magnitud de la pandemia en China, Europa y Estados Unidos, tener casos importados de SARS-CoV-2 (COVID-19), en nuestro país; es difícil no preocuparse cuando se tenía el conocimiento de las condiciones en las que el sector salud se encontraba producto de una conducta de anarquía y decadente de recursos humanos y económicos. A pesar de las presiones que se ha ejercido en los sistemas de salud nacionales, en la contención y atención de esta pandemia, se han logrado obtener enseñanzas, como la confluencia y colaboración de los diversos grupos científicos, profesionales de la salud y sociedad para obtener diagnósticos rápidos, mejores esquemas de tratamiento, medidas de prevención exitosas, mejoras de la comunicación en salud a la población o bien el desarrollo tecnológico de vacunas en tiempos recortados (citado por Sosa, 2020).

En el periodo 2020 al primer trimestre 2021, época de la pandemia por SARS-CoV-2, en la Comisión Estatal de Conciliación y Arbitraje Médico de Tabasco (CECAMET) se implementó un plan estratégico virtual y guardias, permaneciendo abiertas nuestras instalaciones para atender a la población, sin descuidar la salud de los servidores públicos y

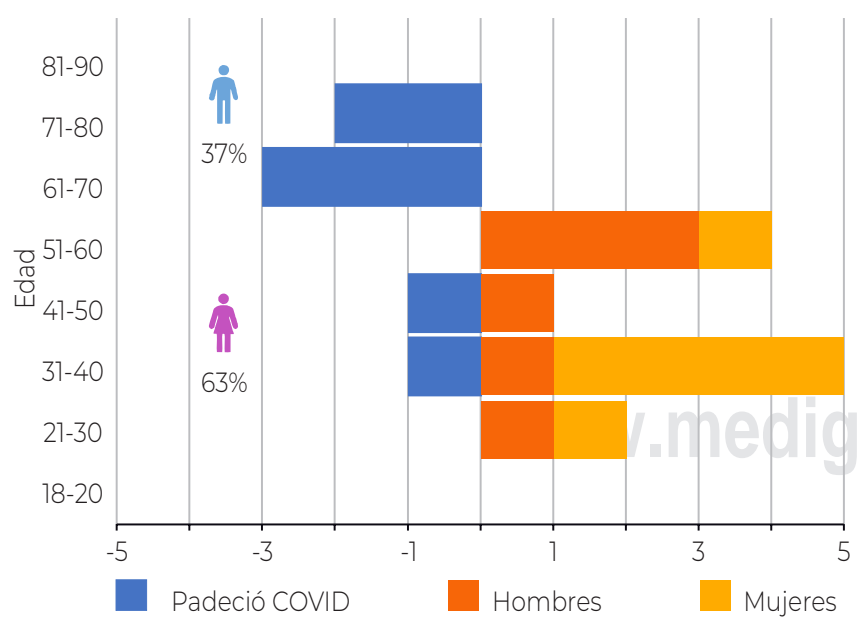

Figura 1: Rango de edad, sexo e infección COVID-19 del personal Comisión Estatal de Conciliación y Arbitraje Médico de Tabasco. la atención efectiva a los usuarios, aplicando las medidas de sanitarias en todo momento.

\section{MATERIAL Y MÉTODOS}

Para la atención efectiva a los usuarios durante el 2020 al primer trimestre 2021 se identificó la población vulnerable entre 50-80 años de edad y el personal que vivía en municipios alejados, estableciéndose el trabajo colaborativo de sus actividades por home office.

En la Unidad de Orientación, Gestión y Asesoría, se llevaron a cabo roles de guardias rotativas, aplicando protocolo sanitario.

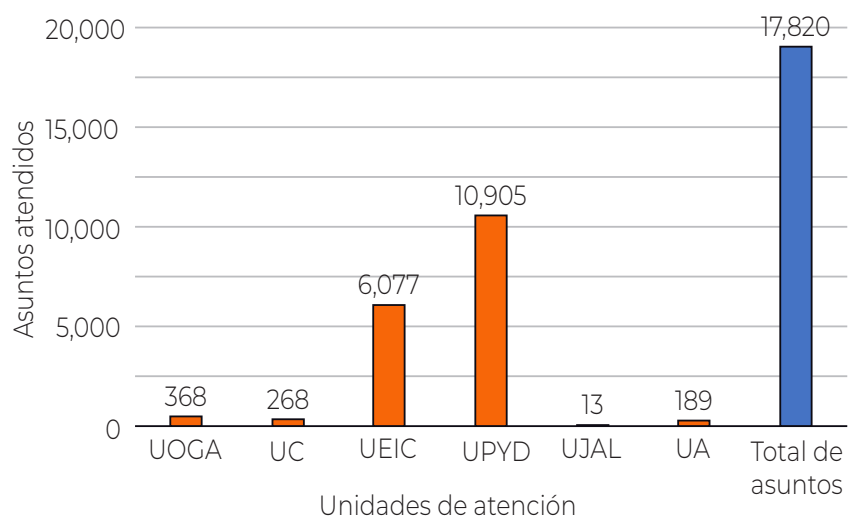

Figura 2: Total de asuntos atendidos en la Comisión Estatal de Conciliación y Arbitraje Médico de Tabasco.

Abreviaturas: $\cup O G A$ = Unidad de Orientación, Gestión y Asesorías, UC = Unidad de Conciliación, UEIC = Unidad de Enseñanza, Investigación y Calidad, UPYD = Unidad de Promoción y Difusión, UJAL = Unidad de Asuntos Jurídicos y Asesoría Legal, UA = Unidad de Arbitraje.

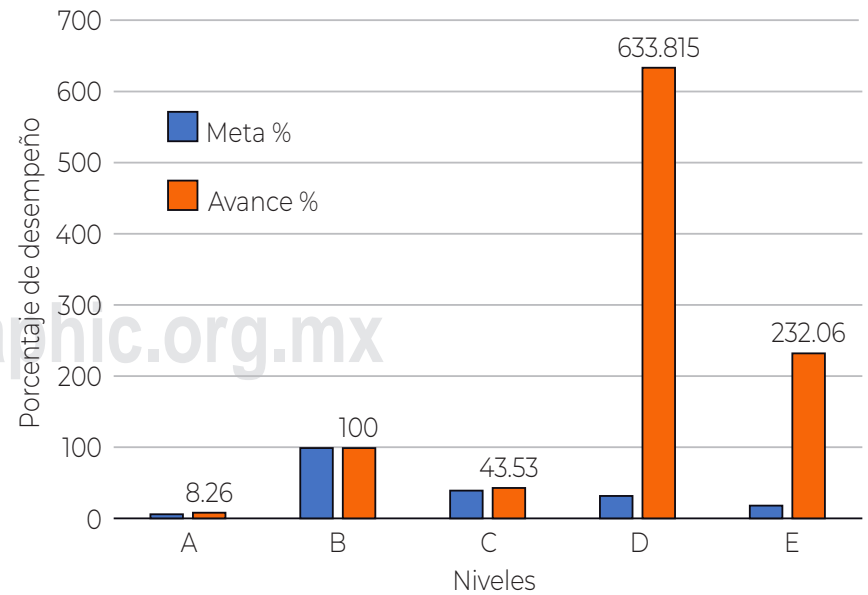

Figura 3: Desempeño por niveles institucionales. 


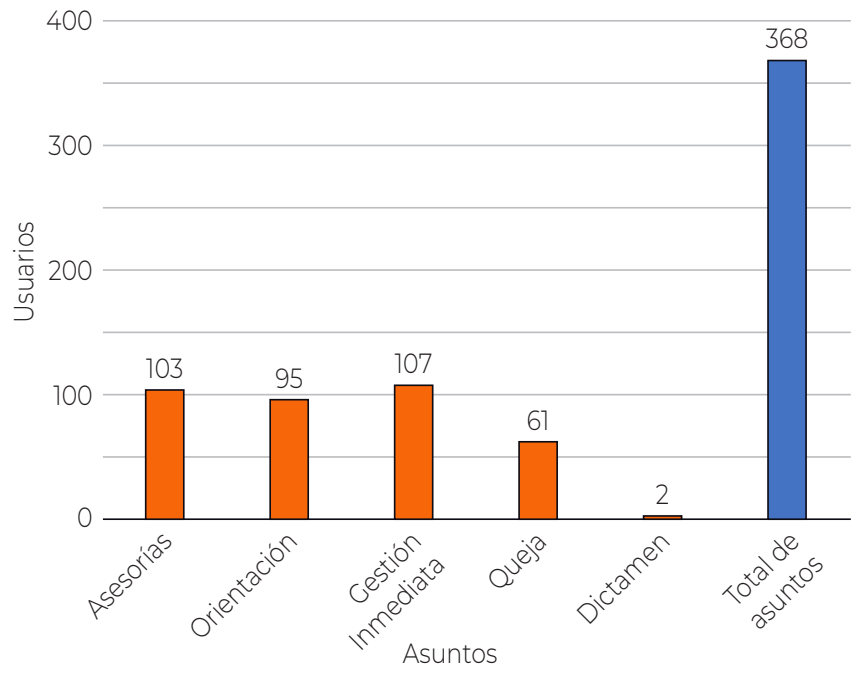

Figura 4: Asuntos atendidos en Unidad de Orientación, Gestión y Asesorías.

Se instaló un buzón a la entrada de la Comisión para atención las 24 horas del día, difundiéndose las vías de entrada de quejas por WhatsApp institucional y buzón virtual publicados en el portal oficial, ${ }^{2}$ atención al usuario en redes sociales por medio de módulos itinerantes virtuales con promoción y difusión de nuestros servicios y prevención contra el SARS-CoV-2, correo electrónico, llamadas telefónicas, protegiendo la seguridad de sus datos personales.

Sellevaron a cabo audiencias y comparecencias por videoconferencia, informando a la población respecto al seguimiento de sus quejas vía telefónica y WhatsApp.

Se reestructuró nuestro Programa de Capacitación Continua (PAEC) hacia el sector salud y público en general, aplicando la modalidad en línea, en nuestra plataforma educativa en Facebook, ${ }^{3}$ así como la apertura del blog 4 institucional.

Para la inscripción a nuestros cursos, evaluación del impacto de nuestra capacitación y aplicación de encuestas de satisfacción de nuestros servicios, se utilizó las apps docs.google.com/forms (Figura 7).

\section{RESULTADOS}

\section{Identificación de población vulnerable CECAMET ante pandemia COVID-19}

Se identificaron nueve servidores públicos ${ }^{5}$ entre la población vulnerable en un rango de edad 51
Tabla 1: Especialidades de los asuntos atendidos en Unidad de Orientación, Gestión y Asesorías.

\begin{tabular}{|c|c|}
\hline Especialidad & Razones \\
\hline $\begin{array}{l}\text { Ginecología y } \\
\text { obstetricia }\end{array}$ & Error quirúrgico \\
\hline $\begin{array}{l}\text { Medicina de } \\
\text { urgencias }\end{array}$ & Retraso del tratamiento \\
\hline Medicina familiar & Retraso del tratamiento \\
\hline Cirugía general & Deficiencias administrativas \\
\hline Nefrología & $\begin{array}{l}\text { Falta de insumos o } \\
\text { medicamentos }\end{array}$ \\
\hline Oncología & Diagnóstico erróneo \\
\hline Urología & Deficiencias administrativas \\
\hline $\begin{array}{l}\text { Odontología } \\
\text { general }\end{array}$ & Deficiencias administrativas \\
\hline $\begin{array}{l}\text { Radiología e } \\
\text { imagen }\end{array}$ & $\begin{array}{l}\text { Retraso del procedimiento } \\
\text { diagnóstico }\end{array}$ \\
\hline
\end{tabular}

a 73 años y tres servidores públicos que viven en municipios alejados a Villahermosa, Tabasco, trasladándose en transporte público, optando el trabajo colaborativo por home office. ${ }^{6}$ Sin embargo, durante el regreso a labores, entre los meses de diciembre a marzo, se reportan siete personas de la oficina que padecieron SARS-CoV-2, de los cuales $63 \%$ son mujeres y $37 \%$ hombres, sin hospitalización o secuelas, resguardándose en sus hogares (Figura 7). No se reportó ningún deceso.

\section{Seguridad de los usuarios}

La comisión realizó medidas para proteger a los usuarios y a los trabajadores, como la aplicación de la vacuna contra influenza y colocar elementos de barrera en los escritorios, proveer de material de limpieza y desinfección constante de las instalaciones, aplicando la sana distancia, aplicación de gel antibacterial, uso de cubrebocas obligatorio y lavado de manos frecuente.

A partir del 25 de febrero de 2020 como parte de las acciones para salvaguardar la seguridad de los usuarios y la protección de sus datos personales, proporcionamos un formato de consentimiento informado, el cual deben firmar para el tratamiento y uso de datos personales, ${ }^{7}$ atendido en 368 casos (Figura 2). 


\section{Acciones de prevención y promoción dirigidas a la población para disminuir morbilidad por SARS-CoV-2}

Se realizaron publicaciones a través de la página oficial de Facebook y canal de YouTube de la CECAMET:

- Vídeo «Cómo será nuestra vida después de la pandemia por la COVID-19» con 155 reproducciones. ${ }^{8}$

- Avisos a la población sobre la manera en que brindaría sus servicios esta comisión derivado de la COVID-19.

- Vídeo motivacional «Nunca perder la esperanza de vivir» con 121 reproducciones. ${ }^{9}$

Tabla 2: Género de los usuarios atendidos en Unidad de Orientación, Gestión y Asesorías.

\begin{tabular}{lc}
\hline Género & Porcentaje \\
\hline Femenino & 57.5 \\
Masculino & 42.5 \\
\hline
\end{tabular}

Tabla 3: Instituciones involucradas en los Asuntos atendidos en Unidad de Orientación, Gestión y Asesorías.

Instituciones involucradas

Instituciones públicas

IMSS

SS

PEMEX

ISSET

ISSSTE

Instituciones privadas

Consultorios

Clínicas

Hospitales

Laboratorio y gabinete

IMSS = Instituto Mexicano del Seguro Social, SS = Secretaría de Salud, PEMEX = Petróleos Mexicanos, ISSET = Instituto de Seguridad Social del Estado de Tabasco, ISSSTE = Instituto de Seguridad y Servicios Sociales para los Trabajadores del Estado.

\section{Evaluación del desempeño}

Implementamos el sistema de indicadores de evaluación del desempeño por niveles de atención ${ }^{10}$ (Figura 3): A) contribuir y consolidar a la CECAMET como instancia prioritaria para resolver los conflictos generados entre los usuarios y los prestadores de servicios de salud niveles estratégicos, B) usuarios de los servicios, C) acciones de prevención y resolución de inconformidades y controversias atendidas, D) capacitación del personal de salud y E) difusión de servicios CECAMET, cumpliendo al $100 \%$ de la meta programada (Figura 3).

\section{Asesorías, gestiones y orientaciones}

Se llevaron a cabo roles de guardias rotativas, aplicado las medidas de higiene y sanidad; las vías de captación fueron: presenciales, telefónica, WhatsApp, redes sociales, buzón, correo electrónico, detallando los alcances de la CECAMET para la resolución de las inconformidades (Tablas 7 a 3) a 368 usuarios según datos de SAQMED (2021) (Figura 4)."

\section{Motivo de queja}

- Falso negativo en estudio PCR para COVID-19

- Atención de COVID-19 por personal no capacitado

- Mala comunicación de médico a familiares con respecto al pronóstico

- Síntomas atípicos con COVID-19 por la mala comunicación con alta voluntaria

- Paciente por crisis convulsivas acude a medio particular con hallazgos sospechoso de COVID-19 con alta voluntaria

Cénero de pacientes

20\% Masculino

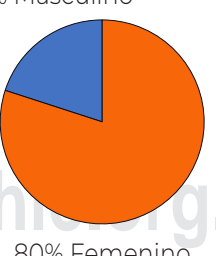

80\% Femenino

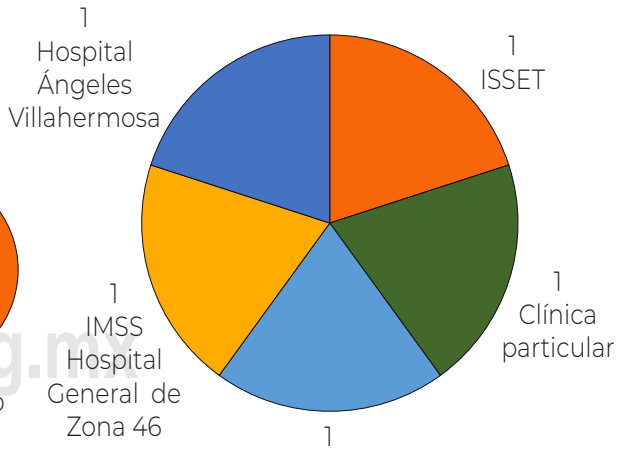

Hospital Regional Dr. Juan Graham Casasús
Figura 5: Inconformidades recibidas por COVID-19 en Unidad de Orientación, Gestión y Asesorías.

Abreviaturas: ISSET = Instituto de Seguridad Social del Estado de Tabasco, IMSS = Instituto Mexicano del Seguro Social. 
Tabla 4: Motivos de las inconformidades recibidas por COVID-19 en Unidad de Orientación, Gestión y Asesorías.

\begin{tabular}{|c|c|c|c|}
\hline $\begin{array}{l}\text { Tipo de } \\
\text { servicio }\end{array}$ & Motivo de inconformidad & Institución & Especialidad \\
\hline Queja & Falso negativo en estudio PCR para COVID-19 & ISSET & Medicina familiar \\
\hline Queja & $\begin{array}{l}\text { Atención de COVID-19 por } \\
\text { personal no capacitado }\end{array}$ & Clínica particular & Neumología \\
\hline Queja & $\begin{array}{l}\text { Mala comunicación de médico a } \\
\text { familiares con respecto al pronóstico }\end{array}$ & $\begin{array}{l}\text { Hospital Regional } \\
\text { «Dr. Juan Graham Casasús» }\end{array}$ & Medicina General \\
\hline Queja & $\begin{array}{l}\text { Síntomas atípicos con COVID-19 por la } \\
\text { mala comunicación con alta voluntaria }\end{array}$ & IMSS & Urgencia pediátrica \\
\hline Queja & $\begin{array}{l}\text { Paciente por crisis convulsivas acude a } \\
\text { medio particular con hallazgos sospechoso } \\
\text { de COVID-19 con alta voluntaria }\end{array}$ & $\begin{array}{l}\text { Hospital Ángeles } \\
\text { Villahermosa }\end{array}$ & $\begin{array}{l}\text { Medicina de } \\
\text { Urgencias }\end{array}$ \\
\hline
\end{tabular}

ISSET = Instituto de Seguridad Social del Estado de Tabasco, IMSS = Instituto Mexicano del Seguro Social.

De las inconformidades recibidas por COVID-19 durante este periodo (Tabla 4), se reportaron cinco usuarios atendidos en donde el mayor motivo fue mala relación médico-paciente con mal pronóstico, en la cual el paciente se dio de alta voluntaria. Estos casos no se lograron conciliar (Figura 5).

\section{Conciliación y arbitraje}

Durante el 2020 al primer trimestre del 2021 se han realizado como acciones de consolidación: audiencias y comparecencias por videoconferencia, atendiendo un total de 268 asuntos concluidos, sin poner al personal y usuarios en riesgo (Figura 6).

La Unidad de Arbitraje realizó audiencias virtuales, e informó a la población respecto del seguimiento de sus quejas vía telefónica y WhatsApp, así como brindando asesorías e implementando un buzón para la recepción de documentación. Fueron atendidos un total de 189 asuntos (Figura 7).

\section{Enseñanza, investigación y calidad}

El Programa Anual de Enseñanza «PAEC 2020»"2 se reestructura aplicando la capacitación del sector de salud en la modalidad en línea en nuestra plataforma virtual en Facebook, ${ }^{3}$ beneficiando a un total de 5,139 usuarios; así como la apertura del blog 4 institucional con 122 beneficiados. Respecto a la participación ciudadana y evaluación de nuestros servicios, aplicamos 309 encuestas de calidad con $98 \%$ de satisfacción de nuestros servicios reportado en PBR (2021), ${ }^{10}$ utilizando las apps docs.google.com/forms, también durante el primer trimestre del 2021, se capacitaron a 600 usuarios sobre el indicador «Prevención y resolución de inconformidades relacionadas con la salud de niños, niñas y adolescentes», de los cuales se atendieron seis casos concluidos (Figura 8).

\section{Difusión y Promoción de servicios}

Se instalaron ocho módulos itinerantes presenciales en los municipios: Paraíso Villahermosa y Comalcalco, aplicando las medidas sanitarias correspondientes; 18 módulos virtuales en nuestra red social Facebook «Módulo itinerante de atención ciudadana», reportando un total de 5,474 beneficiados (Figura 9); nos presentamos en medios de comunicación ${ }^{13}$ en programas de noticias locales TVT, Telerreportaje en radio, Radiofórmula y periódico Tabasco Hoy. Promocionamos temáticas sobre derechos del paciente, profesionales de la salud, normativa en salud, principios aplicables y servicios CECAMET, difundiendo material didáctico en redes sociales. ${ }^{14}$ Se aumentaron nuestras redes sociales a seis: Facebook, Twitter, Instagram, 
YouTube Pinterest y WhatsApp, captando asesorías personalizadas.

\section{Asuntos jurídicos y legales}

Se lograron firmar siete convenios institucionales, así como tres capacitaciones al personal de la

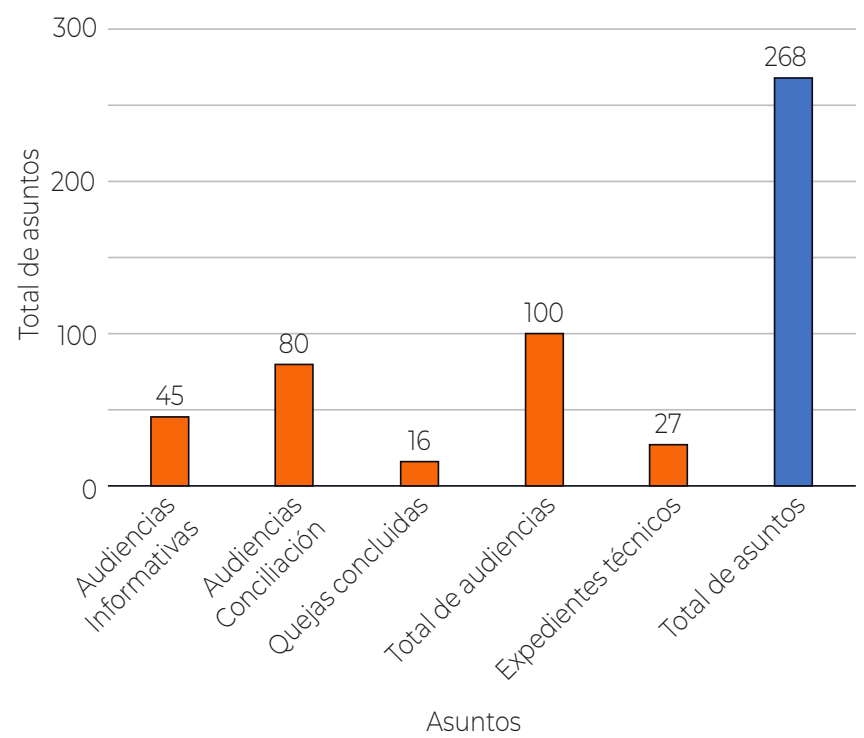

Figura 6: Asuntos atendidos en la Unidad de Conciliación.

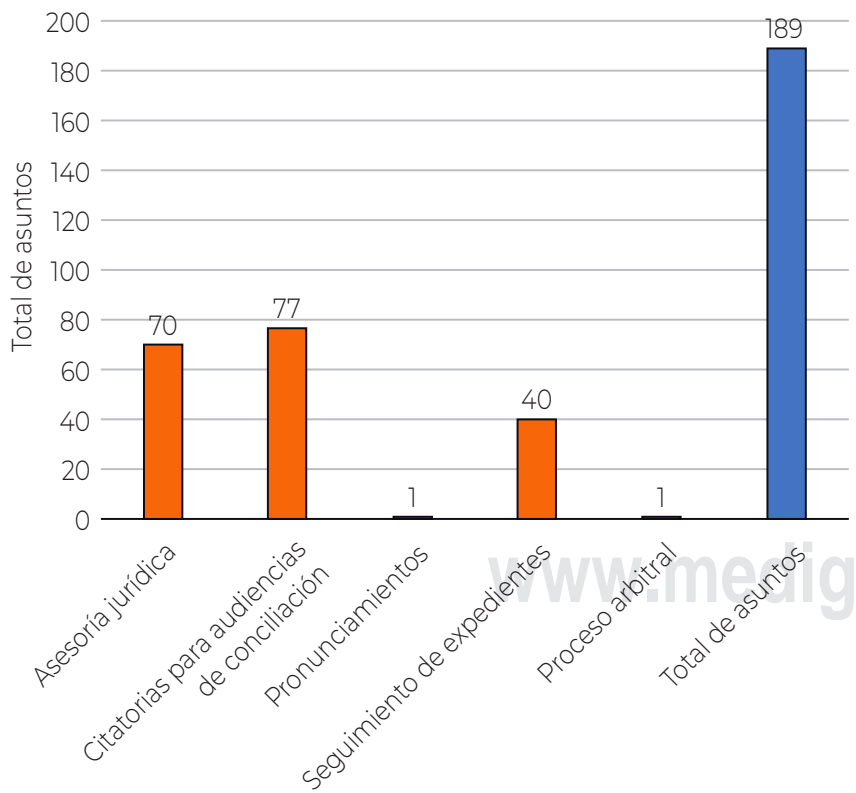

Asuntos

Figura 7: Asuntos atendidos en la Unidad de Arbitraje.
CECAMET y tres programaciones de modificación del estatuto y normatividad, concluyendo 13 asuntos (Figura 10).

\section{CONCLUSIÓN}

- Implementación de estrategias innovadoras, usando las TIC'S, para facilitar la atención al usuario.

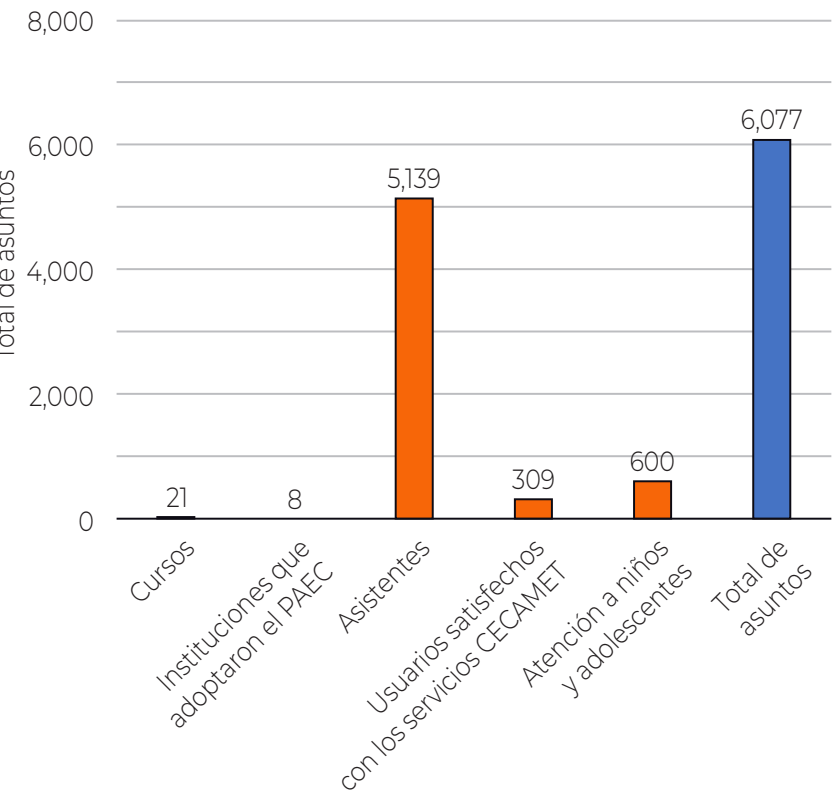

Asuntos

Figura 8: Asuntos atendidos en la Unidad de Enseñanza, Investigación y Calidad.

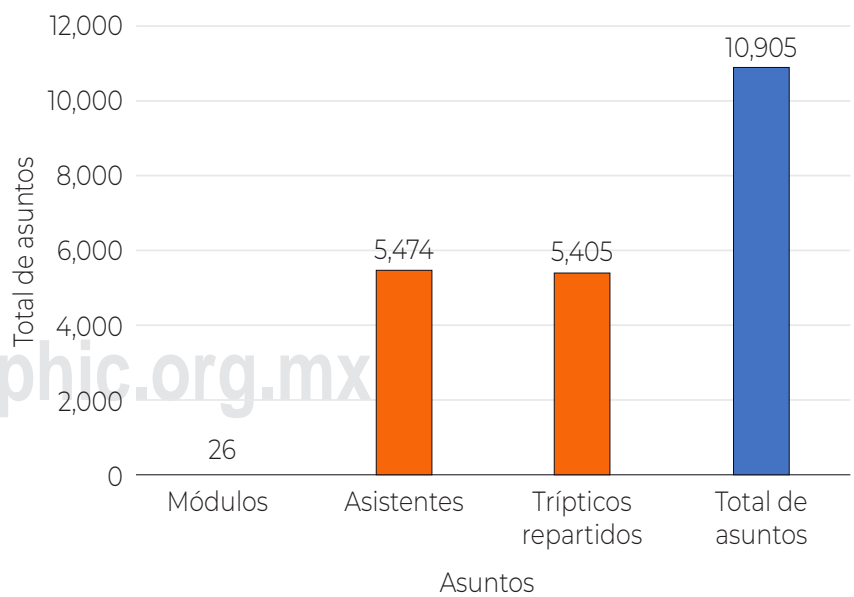

Figura 9: Asuntos atendidos en la Unidad de Promoción y Difusión. 


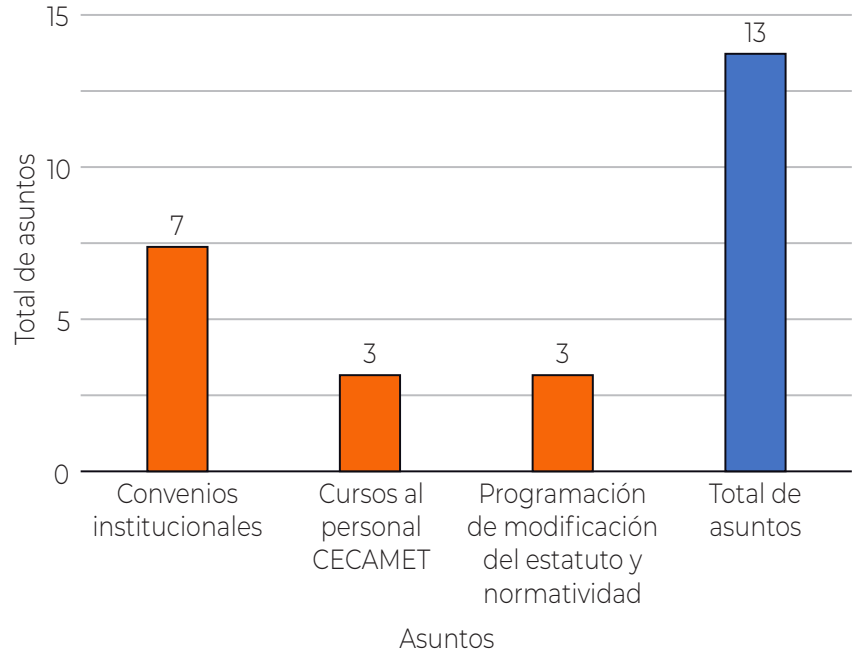

Figura 10: Asuntos atendidos en la Unidad de Asuntos jurídicos y legales.

- Integración primordial de unidades administrativas, logrando mejoras en el servicio.

- Atraso del seguimiento a quejas y expedientes técnicos, por falta de respuesta inmediata de las instituciones de salud, enviando apercibimientos por área jurídica, ante la solicitud de expedientes y gestiones al servicio de los pacientes.

- Retraso en la conciliación y riesgo sanitario al presentarse con SARS COV-2, algunos usuarios y prestadores de salud.

\section{Recomendaciones}

- Es importante la profesionalización constante del servidor público en el uso de herramientas tecnológicas digitales para personalizar y mejorar los servicios otorgados.

- Participación colaborativa y comunicación, facilitando procesos administrativos.

- Aplicar un plan estratégico sanitario obligatorio de abordaje al usuario.

- Mejora continua y expansión de los servicios son estrategias que se deben implementar.

\section{REFERENCIAS}

1. Sosa CJO. Atención de pacientes con COVID-19 en el consultorio médico. Rev CONAMED. 2020; 25 (Suppl. 1): 4-14. Disponible en: https://dx.doi. org/10.35366/97343

2. https://tabasco.gob.mx/cecamet

3. https://www.facebook.com/ESCUELAVIRTUALCECAMET/

4. https://ueiccecamett.wixsite.com/website

5. https://drive.google.com/drive/folders/15ILDbt3lxR4GfXgg tR7gMzwvg2D39AyV

6. https://drive.google.com/drive/folders/1c4WLeAGIAZuQ9V KZHQTWkVugQKWLKSu6? usp=sharing

7. https://transparencia.tabasco.gob.mx/media/ CECAMET/2020/7/527406.pdf

8. https://www.facebook.com/cecametoficial/ videos/3267861999944683

9. https://www.facebook.com/cecametoficial/ videos/3356294241101458

10. Plataforma Nacional de Presupuesto Basado en Resultados (PBR).2027

11. Sistema Nacional de Registro de la Queja Médica (SAQMED). 2021.

12. https://tabasco.gob.mx/sites/default/files/users/ cecamettabasco/PAEC\%202020-7.pdf

13. https://www.youtube.com/watch?v=cpZ_aLWosd8\&t=149s

14. https://www.facebook.com/cecametoficial 